\title{
Geophysical Reconnaissance of Housing Area in Klebang and Sinkhole Occurences in Jeram, West Malaysia
}

\author{
Riyadh Yassin and Ros Fatihah Muhammad
}

(Department of Geology, Universiti Malaya)

\begin{abstract}
s
Geophysical reconnaissance in two areas of different landuse has been carried out. Housing area in Klebang and Jeram shows some degree of difference of subsurface morphology. Subsurface karst in Klebang shows rather undulating limestone platforms while many cavities believed to be water conduits appear in Jeram. A rapid increase of sinkholes occurrences were reported after the disasterous $26^{\text {th }}$ Dec. 2004 earthquake in Sumatera. Many cavities are present here are only covered by thin layers of loose sands and clay materials. These cavities are thought to be preexisting features that had been rapidly filled with sand/clay, due to the tremor triggered by the earthquake.
\end{abstract}

